\title{
Argumentação representativa, justiça eleitoral e democracia deliberativa: sobre a le- gitimidade constitucional da justiça eleitoral ${ }^{1}$
}

\begin{abstract}
Representative argumentation, electoral justice and deliberative democracy: on the constitutional legitimacy of electoral justice
\end{abstract}

\section{Alejandro Nava Tovar ${ }^{2}$}

Resumo: O objetivo deste ensaio reside em explicar a relação entre argumentação representativa, entendida como fundamentação racional e democrática de decisões autoritativas no campo do direito, com a legitimidade da justiça eleitoral, entendida como os meios legais que permitem garantir a validade das eleições e salvaguardar os direitos políticos dos indivíduos, a fim de sustentar que a racionalidade da justiça eleitoral constitui um critério de legitimidade das democracias

1 Traduzido por Camila Silva Baeta, a partir do original escrito em espanhol, Argumentación representativa, justicia electoral y democracia deliberativa. En torno a la legitimidad constitucional de la justicia electoral. Revisão da tradução por Isabel Cristina Campos Vieira do Nascimento.

2 Doutor em Filosofia pela UAM Iztapalapa. Ex-bolsista do DAAD. ProfessorPesquisador de Filosofia do Direito e Argumentação Jurídica no Instituto Nacional de Ciências Penais (INACIPE). Membro no México do Sistema Nacional de Investigadores (SNI 1). ORCID: 0000-0002-5770-5998. 
constitucionais modernas. Para isso, na primeira seção explicarei a relação entre argumentação e democracia deliberativa, na segunda seção reconstruirei a ideia de justiça eleitoral como representação argumentativa, na terceira seção explicarei a dupla dimensão da justiça eleitoral e, finalmente, na última seção, farei algumas considerações sobre o ativismo judicial em matéria de justiça eleitoral.

Palavras-chave: Argumentação, Democracia, Política, Justiça, Representação.

Abstract: The purpose of this essay is to explain the relation between representative argumentation, understood as the rational and democratic justification of authoritative decisions in the field of law, with the legitimacy of electoral justice, understood as the legal ways that guarantee the validity of the elections and, thus, to safeguard the individuals' political rights, in order to justify the rationality of electoral justice as a criterion of legitimacy of modern constitutional democracies. Thereby, in the first section I explain the relation between argumentation and deliberative democracy, while in the second section I make a reconstruction of the idea of electoral justice as an argumentative representation; later, in the third section, I develop the dual dimension of electoral justice and, finally, in the last section, I carry out some considerations on judicial activism regarding electoral justice.

Keywords: Argumentation, Democracy, Politics, Justice, Representation. 


\section{Introdução}

Na cultura jurídica latino-americana, a ascensão da argumentação jurídica teve um impulso decisivo a partir das obras de Robert Alexy, ${ }^{3}$ Neil MacCormick, ${ }^{4}$ Jerzy Wróblewski, ${ }^{5}$ Aulis Aarnio, ${ }^{6}$ Aleksander Peczenik ${ }^{7}$ e Manuel Atienza ${ }^{8}$ Esse auge, produto do Zeitgeist da "reabilitação da razão prática" (Rehabilitierung der praktischen Philosophie), ${ }^{9}$ isto é, o esforço de que a filosofia esteja relacionada ao raciocínio moral, político e jurídico, com as consequências que isso implica, pode sintetizar a pretensão de que os resultados das decisões jurídicas autoritativas não se baseiam em discricionariedade ou irracionalidade do juiz, mas em argumentos fundados e justificados em termos racionais e jurídicos, isto é, através de razões válidas expressadas como fundamentação para as decisões judiciais. Do mesmo modo, essa concepção da virada argumentativa no direito tem três funções primordiais: em primeiro lugar, permite descrever como são elaborados os argumentos jurídicos (função descritiva); em segundo lugar, permite reprovar racionalmente argumentos jurídicos não fundamentados (função crítica) e, em terceiro lugar, permite fundamentar racionalmente os argumentos jurídicos (função normativa).

Se partimos da concepção alexyana da argumentação jurídica como um caso especial da argumentação prática, quer dizer, como um modelo de argumentação que faz re-

\footnotetext{
3 ALEXY, 1978.

4 MAcCORMICK, 1994.

5 WRÓBLEWSKI, 1971, p. 409-419.

6 AARNIO, 1987.

7 PECZENIK, 1989.

8 ATIENZA, 2013.

9 Cf. RIEDEL, 1972-1974.
} 
ferência a questões práticas - levanta uma pretensão de correção (Anspruch auf Richtigkeit) e possui suas respectivas diferenças ou limitações institucionais em relação ao discurso prático ${ }^{10}$ pode-se entender que a razão e a correção no discurso jurídico são possíveis sempre que a argumentação jurídica for analisada à luz de certos procedimentos racionais. A ideia de que a racionalidade jurídica é possível a partir da análise crítica da argumentação jurídica teve um efeito de irradiação a todos aqueles que aspiram uma legitimidade do raciocínio jurídico, como pode ser visto nas diversas posições em torno da racionalidade jurídica que vão desde as posições de tipo weberiano sobre a racionalização do direito moderno, ${ }^{11}$ luhmanniano, segundo a qual a legitimidade está mediada por procedimentos legais, ${ }^{12}$ até a posição alexyana do caso especial, segundo a qual o discurso jurídico é uma espécie de discurso prático. ${ }^{13}$ Basta mencionar essas posições para entender a importância dos procedimentos legais para alcançar o ideal de racionalidade jurídica. Mas o que importa para mim agora é analisar a importância da justiça eleitoral, em virtude de sua importância para a consolidação da democracia deliberativa. Por isso, sob o aspecto crítico e normativo da argumentação jurídica, analisarei a legitimidade da justiça eleitoral.

\footnotetext{
10 ALEXY, 1978, p. 263.

11 Cf. WEBER, 1976, p. 126-130.

12 Cf. LUHMANN, 1997.

13 De acordo com uma entrevista de Alexy, em Teoria da Argumentação Jurídica, ele tentou defender duas teses que, à primeira vista, parecem contraditórias. A primeira afirma que a argumentação jurídica racional não é possível sem argumentos práticos gerais. A segunda afirma que a argumentação jurídica deve levar a sério a validade do direito positivo. Alexy tentou desfazer essa tensão por meio da tese do caso especial. Cf., ALEXY, 2014, p. 259.
} 


\section{A argumentação e democracia deliberativa}

A relação entre raciocínio jurídico e justiça eleitoral constitui um dos pilares da democracia moderna. Realizar uma reconstrução das diferentes concepções clássicas e modernas de democracia não é possível nem necessário neste ensaio; basta indicar aspectos básicos das ideias modernas da teoria democrática. Em diversas correntes dessa teoria, pode ser percebida uma tendência a considerar a democracia em termos formais e representativos. Embora essa distinção não seja a única, continua sendo a mais prevalente em vários círculos acadêmicos. A partir da ideia de democracia representativa estabelecida na modernidade surge uma diferença irredutível surge entre os governantes e os governados. Essa diferença tornou-se maior em sociedades modernas complexas, ${ }^{14}$ nas quais é necessário que o poder político seja delegado aos representantes do povo. Não obstante, a democracia moderna, definida através de quatro características - estatalidade, igualdade de direitos dos cidadãos, competência política e responsabilidade dos Estados $-{ }^{15}$ pode ser amplamente concebida mediante quatro diferentes modelos que descreverei a seguir. ${ }^{16}$

O primeiro modelo é o da democracia direta ou ateniense, o ideal clássico e, até certo ponto, nostálgico da polis grega, que vai desde a concepção clássica dos gregos, passa pelos caminhos da filosofia política de Rousseau e encontra uma reabilitação na questão da autonomia de Castoriadis. ${ }^{17}$ No entanto, esse modelo normativo é questionado por ser

14 FUCHS, 2009, p. 42.

15 OFFE, 2011, p. 88.

16 Sobre uma análise desses quatro modelos, cf. CELIKATES e GOSEPATH, 2013, p. 196.

17 Cf. ROUSSEAU, 1971; CASTORIADIS, 2005, p. 103-128. 
considerado impraticável sob as condições das sociedades modernas complexas. O segundo modelo é o da democracia indireta ou representativa, modelo formal que compreende a democracia como um conjunto de regras (primárias ou fundamentais) que estabelecem quem está autorizado a tomar decisões coletivas e sob quais procedimentos. ${ }^{18}$ Esses modelos são geralmente considerados antagônicos, pois contrastam a participação direta da democracia antiga com a representação política da democracia representativa, embora seja preciso apontar que não deve ser sublimado ou exagerado o igualitarismo do modelo clássico, como corretamente colocado por Rodríguez Zepeda. ${ }^{19} \mathrm{O}$ terceiro modelo contemporâneo é o da democracia radical, que oscila entre concepções pessimistas, céticas ou críticas do ideal democrático, em franca oposição às concepções processuais e liberais da democracia. ${ }^{20}$ Finalmente, o quarto modelo é o da democracia deliberativa, que teve um desenvolvimento importante a partir da expressão "política deliberativa" (deliberative Politik), cunhada por Habermas a partir de Facticidade

18 Cf, BOBBIO, 2007, p. 24.

19 Segundo Rodríguez Zepeda, “a democracia antiga poderia ser praticada e justificada com base em um substrato social de profundas desigualdades - de riqueza, de gênero, de idade, de nacionalidade, de dignidade -; no entanto, a democracia moderna, que surgiu no século XIX e se consolidou de acordo com seu conceito no século XX, implica pressupostos igualitários que lhe são inerentes e que, se negados, anulariam o próprio conceito de governo democrático. A democracia grega foi fundada sobre um modelo social excludente e discriminatório em relação às categorias sociais que hoje são vistas como participantes obrigatórios e de pleno direito na democracia de hoje. É por isso que não há dúvida de que o valor da igualdade na democracia moderna é mais poderoso do que no ateniense, porque não apenas reivindica a paridade política dos cidadãos, mas, consideradas exceções razoáveis, tende a identificar toda pessoa com um cidadão" (ZEPEDA, 2014, p. 230).

20 Cf. OFFE, 2008, p. 37; MOUFFE e LACLAU, 2004; DE SOUSA, 2014, p. 357362. 
evalidade. ${ }^{21}$ Ora, um ponto-chave deste último modelo é que, sem cair em tendências pessimistas, próprias do modelo radical, ele busca mediar os projetos de democracia direta e representativa. Isso é possível mediante a introdução da dimensão argumentativa na esfera pública (Öffentlichkeit). A democracia deliberativa está baseada na participação dos cidadãos em um intercâmbio livre e racional de argumentos na busca de argumentos politicamente corretos para todos.

De acordo com a ética discursiva, base dessa concepção deliberativa de democracia, uma norma "somente pode aspirar a ter validade quando as pessoas afetadas conseguem concordar (ou podem concordar), enquanto participantes de um discurso prático, que a referida regra é válida". ${ }^{22}$ Conforme a validade desse postulado ético discursivo (D), deve-se argumentar racionalmente que o conteúdo normativo da linguagem prescritiva deve ser capaz de se universalizar para que uma norma seja válida. Esse princípio de universalização (U) pode ser aprovado quando todos os afetados puderem aceitar as consequências que resultam do respeito a essas normas, sempre que elas sejam preferíveis às de outras alternativas possíveis. ${ }^{23}$

Por isso, essa concepção argumentativa da democracia oferece um fundamento não instrumental das instituições democráticas ${ }^{24}$ e responde, assim, aos desafios da legitimidade do poder do Estado e a um constitucionalismo genuinamente deliberativo que conecta o direito à moral e à política. No entanto, o princípio democrático, um dos fundamentos do

\section{Cf. HABERMAS, 1992.}

22 HABERMAS, 1994, p. 86.

23 Sobre o esclarecimento em torno do princípio da universalização (U) e da fórmula discursiva (D), cf. HABERMAS, 1991, p, 32.

24 Sobre a distinção entre fundamentos instrumentais e não instrumentais da democracia, cf. CELIKATES e GOSEPATH, 2013, p. 202. 
Estado de Direito, responde ao problema da atribuição de poder no Estado. ${ }^{25}$ Essa atribuição de poderes aos órgãos estatais corresponde a uma divisão básica segundo a qual os poderes estatais devem funcionar como contrapesos uns dos outros para assegurar um dos elementos essenciais dos estados democráticos de direito: os direitos fundamentais dos indivíduos. Um dos elementos essenciais do Estado de Direito é constituído precisamente por um sistema de direitos fundamentais, isto é, um tipo de direitos subjetivos cuja differentia specifica para os demais reside em sua fundamentalidade, já que, embora um direito fundamental seja um direito subjetivo, nem todo direito subjetivo é fundamental. ${ }^{26}$ Essa fundamentalidade reside no fato de que, do ponto de vista constitucional, sua atribuição ou negação a um indivíduo não pode permanecer nas mãos da maioria parlamentar simples". ${ }^{27}$

No entanto, dentro da categoria de direitos fundamentais, encontramos os direitos políticos, isto é, os direitos que permitem aos cidadãos participar com igualdade de oportunidades nos processos de formação de opinião e vontade comuns, para exercer sua autonomia política, cumprindo, assim, o princípio democrático, que de acordo com um ensaio de Kelsen sobre a defesa da democracia, corresponde à exigência de igualdade de direitos eleitorais. ${ }^{28}$ Como se pode ver, os direitos políticos são de especial importância para o Estado de Direito, pois permitem que seja conferida legitimidade à formação da vontade política. De acordo com esse tipo de direito, os representantes da eleição popular terão legitimidade quando seus cargos forem alcançados

\footnotetext{
25 MASTRONARDI, 2007, p. 252.

26 Cf. BERNAL, 2009, p. 83.

27 ALEXY, 1985, p. 406.

28 KELSEN, 2006, p. 72.
} 
mediante um procedimento legal imparcial, reafirmando a ideia de conceber legitimidade política como resultado de um procedimento legal.

De acordo com o que apresentei até agora, o ideal da democracia como projeto de deliberação permanente se apoia na autonomia dos cidadãos, mas não apenas nessa dimensão ideal. A democracia também está baseada na dimensão real segundo a qual devem existir normas jurídicas e instituições autoritativas que se pronunciem ou decidam sobre os processos ou conflitos surgidos no terreno político. Essa dimensão real nos levará à análise da justiça eleitoral como garantia do projeto de uma democracia deliberativa e, com ela, a conceber o trabalho dessa forma de justiça como uma forma de representação argumentativa, vinculada a esse tipo de democracia deliberativa.

\section{Justiça eleitoral como representação argu- mentativa}

A ideia de uma justiça eleitoral constitui, na modernidade, um notável avanço na construção e consolidação de Estados democráticos de direito. Com o objetivo de proteger os direitos políticos dos cidadãos, a justiça eleitoral é composta pelos diversos meios e procedimentos de impugnação ou controle de atos e procedimentos eleitorais. Esses meios são projetados para garantir a legitimidade constitucional das eleições e para que as mesmas estejam em conformidade com a legalidade que foi instituída para o seu correto funcionamento. Mediante a aplicação da justiça eleitoral, os conflitos eleitorais podem ser resolvidos, com o objetivo de proteger os direitos políticos dos cidadãos. Como em todo âmbito do direito, a justiça eleitoral está submetida a uma concepção argumentativa, na medida em que as controvérsias que sur- 
jam em um conflito político devem ser resolvidas conforme um procedimento que vai além da mera discricionariedade dos juízes.

A justiça eleitoral, então, procura resolver de forma institucional as demandas e as impugnações relacionadas às eleições e aos direitos político-constitucionais dos cidadãos. O exercício dessa faculdade autoritativa é de grande importância para um exercício correto da democracia, assim como para a manutenção do Estado de Direito. Nesse sentido, a argumentação dos juízes em matéria de justiça eleitoral deve contar com uma fundamentação e motivação de especial importância, já que, no caso da justiça eleitoral, os destinatários da sentença não são unicamente as partes interessadas, como ocorre em conflitos em matéria civil ou penal e, além disso, nem apenas o candidato do partido político que desafia um certo resultado eleitoral. No caso da justiça eleitoral, o destinatário final da sentença é a sociedade política em sua totalidade; assim, a argumentação dos juízes eleitorais deve ser mais refinada, sobretudo em contextos políticos e sociais em que a fundamentação racional de sua decisão final dependerá em boa medida da estabilidade social e da legitimidade do poder político.

A justiça eleitoral revelou, então, uma característica distintiva de qualquer argumento jurídico: a pretensão de imparcialidade. Essa pretensão de imparcialidade constitui um elemento básico da dimensão ideal do direito, embora seja difícil de alcançar no âmbito da argumentação jurídica, sobretudo no da justiça eleitoral, um campo no qual os fatores reais do poder (realen tatsächlichen Machtverhältnissen ${ }^{29}$ tendem a pesar mais do que em outros campos. Embora essa pretensão de imparcialidade seja um requisito que nem sempre é cumprido, ela é possível quando a argumentação

29 LASSALLE, 1987, p. 147. 
oferecida pelos juízes é a mais próxima de um diálogo entre três partes. ${ }^{30}$ Ora, mas, por que afirmo que a argumentação jurídica em geral deve se assemelhar a um diálogo entre três partes? O discurso jurídico em geral, diferentemente de outras formas de discurso prático, pressupõe um elemento essencial para se estabelecer como tal: a existência de uma terceira parte que deve ser neutra em relação às pretensões das outras duas partes no conflito. Eé tal imparcialidade que confere caráter autoritativo às suas decisões e dá confiança aos cidadãos de que o sistema eleitoral é legítimo. Por esse motivo, a resolução final deverá ser acatada pelas partes, em benefício da sociedade.

Esse pressuposto do raciocínio jurídico assume especial importância no âmbito eleitoral, pois ele depende de os juízes deixarem de lado tanto suas preferências políticas e ideológicas quanto a influência dos poderes selvagens ${ }^{31}$ no momento da tomada de decisão em torno de uma impugnação ou demanda sobre o âmbito eleitoral. Estamos diante de um grave problema, tanto no âmbito da argumentação quanto na democracia constitucional, já que os juízes, como cidadãos, têm preferências políticas e sofrem pressões sobre suas decisões. Mas, na função de juízes, devem colocá-las de lado no momento de resolver um conflito eleitoral. Em outras palavras, o raciocínio em matéria eleitoral deve fundamentar-se em critérios jurídicos na medida das suas possibilidades jurídicas e factuais, e não em critérios políticos. É nesse ponto que a argumentação jurídica encontra diversos problemas, devido à força das preferências políticas, à pressão dos grupos de poder e ao possível caráter discutível de suas decisões, enquanto essas podem ter consequências importantes para a manutenção do Estado de Direito.

30 Sobre essa ideia, sou grato ao trabalho de Jonathan Gorman, "Three Person Justification", (GORMAN, 2007, p, 207 ss.).

31 Cf. FERRAJOLI, 2011. 
A influência da esfera política é inegável na conformação de certas decisões judiciais em todos os campos. Essa influência pode levar a desvios nos resultados dos processos eleitorais encarregados da proteção do exercício dos direitos políticos. Diante desse possível desvio, a justiça eleitoral tem uma função corretiva, isto é, onde forças políticas podem violar direitos político-eleitorais, a justiça eleitoral deve restabelecer a validade desses direitos fundamentais, apesar da influência dos fatores reais de poder, mencionados anteriormente. O raciocínio jurídico dos juízes é o que deve fundamentar a validade dos processos eleitorais, e não suas preferências políticas, ocultas sob o manto do formalismo ou ativismo jurídico, atitudes que às vezes costumam ser as duas faces da mesma moeda. Essa dimensão argumentativa é o que permite conectar a argumentação e a justiça eleitoral com a defesa da democracia. Dessa maneira, entramos na dimensão da representação argumentativa.

Em um trabalho que se refere à legitimidade do controle constitucional, definido como "a expressão da prioridade ou superioridade dos direitos humanos sobre e contra a legislação parlamentar", 32 Alexy mencionou que um dos problemas que os juízes enfrentam consiste em não contar com legitimidade direta do povo. Não obstante, Alexy afirma que, segundo o constitucionalismo discursivo, o controle da constitucionalidade é uma forma de representação argumentativa do povo. A legitimidade da função dos juízes eleitorais nas democracias modernas reside precisament nessa forma de representação argumentativa,.

Segundo Alexy, assim como o conceito de direito, o conceito de representação, entendido como a relação entre repraesentandum e repraesentans, possui uma dimensão ideal ao levantar uma pretensão de correção. Isso é importante

32 ALEXY, 2005, p. 577. 
porque a democracia não é apenas um sistema de decisões políticas obtidas de qualquer forma, mas também um sistema de argumentação racional. De acordo com essa ideia, a representação do povo é tanto volitiva como argumentativa. Mediante a inclusão da argumentação, a democracia se torna deliberativa, pois permite institucionalizar o discurso como meio de tomada de decisão na sociedade. ${ }^{33} \mathrm{O}$ problema reside no fato de que tanto o controle de constitucionalidade quanto a argumentação em matéria de justiça eleitoral podem ser idealizados em níveis extremos. Um crítico pode objetar que um tribunal supremo ou eleitoral pode declarar qualquer argumento como se fosse em nome do povo, equiparando assim a dimensão ideal à real. Assim, a justiça eleitoral poderia se afastar do que os representados realmente pensam, mas os juízes eleitorais poderiam afirmar que, ao declarar a validade ou invalidade de uma impugnação eleitoral, representam o povo. A pretensão de correção, portanto, poderia não ser suficiente para defender o princípio democrático.

A saída para esse problema é possível sempre e quando possa se estabelecer um vínculo entre o que as cortes deliberam e o que o povo pensa. Alexy conclui que esse vínculo é formado quando se cumpre dois passos. No primeiro passo, o controle da constitucionalidade - neste caso, a justiça eleitoral - deve mostrar que não é qualquer resposta que pode ser dada em um procedimento racional. No segundo passo, não é apenas necessário que os argumentos dos tribunais eleitorais tenham a pretensão de representar o povo, mas que, além disso, um bom número de pessoas deve estar disposto a aceitar a racionalidade dos argumentos emitidos por esse tribunal, porque esses argumentos estão corretos. Assim, Alexy apresenta duas razões fundamentais para uma verdadeira representação argumentativa, as quais permitem

ALEXY, 2005, p. 579. 
que a justiça eleitoral possa garantir, nese caso, o princípio democrático-representativo: (1) a existência de argumentos corretos ou razoáveis oferecidos pelos juízes eleitorais e (2) a existência de pessoas racionais, dispostas e capazes de aceitar argumentos corretos e fundamentados. Essas pessoas, de maneira análoga à "pessoa liberal" de Rawls, podem muito bem ser denominadas "pessoas constitucionais". Desse modo, tanto o controle constitucional como a justiça eleitoral podem ser concebidos como um tipo de argumentação representativa e, portanto, compatível com a democracia.

Não obstante, de acordo com críticos como Mattias Kumm, o problema desse argumento é que, apesar dos argumentos de Alexy estarem corretos, o desacordo racional permanece $^{34}$ enquanto for discursivamente possível. A respeito desse problema, pode-se argumentar que a pretensão de correção não deve ser descartada em virtude do reconhecimento da razoabilidade do desacordo, já que a correção, enquanto ideia regulativa, tem como consequência o fato de que o desacordo ocorrido em meios institucionais deve permanecer aberto a discussões futuras. Dessa maneira, a argumentação dos juízes em matéria eleitoral pode ser concebida como uma forma de representação argumentativa. Essa forma de representação argumentativa está baseada em uma concepção deliberativa de democracia. Assim, a representação argumentativa da justiça eleitoral constitui uma garantia da democracia, apesar da persistência de desacordo institucional dentro dos limites da racionalidade prática.

34 KUMM, 2012, p. 208. 


\section{A dupla dimensão da justiça eleitoral}

Se a democracia moderna é a forma de autodeterminação comunitária e, como tal, é um fim em si mesma, ${ }^{35}$ então "o princípio da maioria, a maior aproximação possível da ideia de liberdade na realidade política, pressupõe como condição essencial o princípio da igualdade". ${ }^{36}$ Esse princípio da igualdade foi configurado como um direito político inalienável na modernidade e protegido pela institucionalização da justiça eleitoral. Ante o perigo de que ocorra uma violação nos procedimentos eleitorais, os juízes dos tribunais eleitorais devem corrigir os atos, acordos e resoluções dos institutos eleitorais que tenham sido impugnados. Desse modo, as instituições encarregadas dos processos eleitorais devem acatar as resoluções do referido tribunal, pois suas sentenças têm uma dimensão autoritativa. É por isso que as teorias sobre o raciocínio jurídico - tanto as teorias focadas no raciocínio interpretativo quanto as focadas no raciocínio probatório - são de especial importância nesse âmbito, já que confirmam os critérios de validade que analisarão, em boa parte, se as decisões jurídicas tomadas pelos referidos tribunais eleitorais estão corretas. Seja para determinar a validade ou invalidade de uma decisão proveniente do âmbito da justiça eleitoral, a argumentação se apresenta como um elemento necessário acerca da razoabilidade da decisão tomada.

Isso leva à compreensão das duas dimensões da justiça eleitoral, as quais também fazem parte da dupla natureza do direito, segundo a concepção de Alexy: por um lado, a dimensão autoritativa, que deve ser capaz de impor suas decisões à instância inferior em favor da democracia. Por outro

35 KERSTING, 2000, p. 206.

36 KELSEN, 2006, p. 284. 
lado, a dimensão ideal da justiça eleitoral, representada por sua pretensão de ser uma justiça imparcial, independentemente das preferências políticas dos juízes encarregados por esse tipo de justiça. Essa dimensão ideal se expressa mediante a fundamentação da argumentação racional dos juízes em favor de uma decisão de especial interesse para a formação de um Estado democrático. Aqui aparece com suficiente força o giro argumentativo do direito, aplicado à justiça eleitoral e à defesa dos direitos fundamentais em matéria eleitoral.

Portanto, a defesa da democracia constitucional moderna também depende da racionalidade dos argumentos que tentam justificar uma decisão jurídica no campo da justiça eleitoral. Não obstante, essa defesa da democracia não precisa apenas de juízes críticos em matéria eleitoral, mas requer também uma sociedade deliberativa, que deve exigir dos juízes eleitorais conhecimentos específicos no âmbito do raciocínio jurídico e um setor acadêmico crítico, isto é, livre de compromissos políticos no momento de avaliar decisões judiciais e possuidor de conhecimentos atualizados sobre o raciocínio jurídico para servir como guia reflexivo à opinião pública. ${ }^{37}$ No fundo dessa discussão está, mais uma vez, o antigo dilema entre Sócrates e Cálicles, entre "educar o poder da razão para rechaçar as razões do poder", ${ }^{38}$ entre uma ideia de justiça eleitoral que serve à concepção democrática de Estado como uma representação argumentativa e uma

37 Não obstante, na dimensão real ou fáctica, é frequente ver que os setores acadêmicos têm compromissos políticos e isso os leva a preferir certos temas ou a criticar com maior ou menor atenção certas decisões judiciais. Do mesmo modo, apesar de ter acesso a conhecimentos mais especializados, poucas vezes o setor acadêmico aproveita estas possibilidades. Por exemplo, sobre o exame da proporcionalidade, pude comprovar como interpretações errôneas e a falta de conhecimento crítico e direto resultaram em malentendidos notáveis entre aqueles que afirmam estudar a argumentação jurídica.

38 BOBBIO, 1989, p. 379. 
concepção não democrática de Estado, que afeta seriamente os direitos político-fundamentais dos indivíduos de escolher livremente seus governantes. A argumentação, assim, apresenta-se como uma característica necessária à fundamentação das decisões judiciais no âmbito da justiça eleitoral.

\section{Sobre $o$ ativismo judicial eleitoral}

O estudo da argumentação jurídica teve um efeito de irradiação na questão do ativismo judicial. Embora essa forma de ativismo tenha gerado diversos debates tanto a favor quanto contra a dita atividade dos juízes, em matéria eleitoral ela geralmente suscita mais problemas do que em outras áreas do direito. A razão é evidente: em uma sociedade democrática, a politização ou moralização dos argumentos no âmbito do direito eleitoral por parte dos juízes não é vista apenas como uma invasão ilegítima de competências, mas também como perigosa para a estabilidade das democracias. Os fatores reais de poder interferiram, não com pouca frequência, na determinação de importantes resoluções em matéria eleitoral na América Latina, uma situação preocupante para aqueles que consideram que a legitimidade do processo democrático pode se quebrar diante de um mero decisionismo de tribunal schmittiano.

Embora nem todo ativismo judicial seja condenável (ao menos não para a opinião pública e os defensores dos direitos humanos), ${ }^{39}$ devemos ser cautelosos para aceitar

39 Penso na legitimidade pública do juiz Baltasar Garzón, que em 2008 se declarou competente para averiguar sobre cerca de 100.000 desaparecimentos forçados durante o período franquista. Apesar das fortes críticas ao ativismo de Garzón, os sinais de apoio ao seu ativismo tiveram maior peso. $\mathrm{O}$ caso de Garzón mostra que nem todo ativismo judicial é condenável aos olhos da opinião pública ou da academia. No entanto, seria um erro considerar todo ativismo judicial como genuíno ato de justiça. Nesse sentido, penso na decisão do juiz Sérgio Fernando 
que a ideologia política do juiz invada a esfera jurídica no âmbito da justiça eleitoral, já que ele não pode ser juiz e parte do processo de formação da vontade política de um Estado de Direito, uma vez que esse ativismo pode escapar dos controles institucionais e gerar um decisionismo político, no qual a própria democracia seria derrotada em um tribunal justiça eleitoral, violando, assim, o princípio da equidade. As diversas concepções que concebem a legitimidade das decisões por vias procedimentais não o fazem apenas em virtude do formalismo jurídico, atribuído de forma usual aos juízes legalistas, mas porque esse procedimento garante a imparcialidade das decisões judiciais. Nesse sentido, em Uma Teoria da Justiça, Rawls menciona que o estado de direito (Rule of Law) exige um processo para conhecer a verdade por meios de acordos com os outros propósitos do sistema jurídico, e nesse referido processo os juízes devem ser independentes e imparciais, ${ }^{40}$ posto que ninguém pode julgar seu próprio caso. Assim, o estado de direito deve limitar as tendências dos juízes para decidir segundo suas preferências eleitorais, pois, caso contrário, violariam a imparcialidade exigida por uma legalidade reflexiva.

A cultura da legalidade exige mais do que nunca juízes críticos em relação aos problemas contemporâneos da democracia. Sem essa cultura, o sistema jurídico perde sua natureza e se converte em uma ordem predatória, camuflada sob o manto de respeito à lei. É certo que o "poder invisível" ao qual Bobbio ${ }^{41}$ se referia continua à espreita pela democra-

Moro, que comandou a Operação Lava Jato e sentenciou o ex-presidente brasileiro Lula a nove anos e seis meses de prisão. Essa decisão foi objeto de elogios, que apontam essa decisão como um exemplo de imparcialidade, bem como críticas, que veem nessa decisão um uso político e ilegítimo do direito que culminou com o triunfo de Jair Bolsonaro.

40 Cf. RAWLS, 2010, p. 225.

41 Cf. BOBBIO, 2007, p. 94 
cia, e é por essa razão que os juízes encarregados da justiça eleitoral devem lutar com meios legais para salvaguardá-la, tornando-se guardiões da constituição e da democracia, sem usar seu cargo para beneficiar o partido político de sua escolha. Portanto, um ativismo jurídico moderado e crítico pode beneficiar a democracia, sobretudo em tempos de crises institucionais, derivadas da politização da justiça e da ascensão de poderes selvagens, sejam econômicos, midiáticos ou políticos.

\section{Conclusões}

No prefácio de uma compilação de ensaios sobre o problema da "democraticidade" contemporânea, Luis Salazar parafraseou a famosa introdução da História de duas cidades de Charles Dickens ${ }^{42}$ para se referir à situação atual das democracias. Por um lado, esse parecer ser o melhor dos tempos para se falar sobre o triunfo da democracia, pois é possível ver que ela sobreviveu contra suas alternativas autoritárias tanto de direita quanto de esquerda; mas, por outro lado, esse parece ser o pior dos tempos para se falar sobre o triunfo da democracia, pois hoje, mais do que nunca, o ideal democrático está ameaçado por uma globalização anárquica e por poderes fáticos selvagens. ${ }^{43}$

42 "It was the best of times, it was the worst of times, it was the age of wisdom, it was the age of foolishness, it was the epoch of belief, it was the epoch of incredulity, it was the season of Light, it was the season of Darkness, it was the spring of hope, it was the winter of despair, we had everything before us, we had nothing before us, we were all going direct to Heaven, we were all going direct the other way - in short, the period was so far like the present period, that some of its noisiest authorities insisted on its being received, for good or for evil, in the superlative degree of comparison only." (DICKENS, 1999, p. 1).

43 Cf. SALAZAR, 2014, p. 7. 
Embora essas posições extremas tendam a governar oa parte dos discursos acadêmicos hoje em dia, é certo o meio termo abriga uma postura sensata, embora isso faça a democracia parecer mais um purgatório secular do que um sociedade bem organizada. Independentemente de escolhermos alguma dessas visões para expressar nossa visão do que é e deve ser a democracia, o certo é que os conflitos entre poderes políticos e econômicos permanecerão lá, tentando subordinar o direito ao poder político, sobretudo nas democracias em permanente estado de construção, como as latino-americanas. Portanto, os juízes em matéria eleitoral devem estar preparados para enfrentar esses poderes visíveis e invisíveis. Independentemente de suas preferências políticas, os juízes devem lutar pela legalidade da justiça eleitoral sem esquecer a legitimidade de suas decisões. Somente assim as instituições poderão ganhar a confiança dos cidadãos e contribuir para a democratização das sociedades políticas modernas.

Se meus argumentos estão corretos, a pretensão de conceber a justiça eleitoral como uma forma de representação argumentativa da sociedade se torna então uma pretensão necessária e mais importante do que nunca, sobretudo no âmbito das democracias latino-americanas, sempre inclinadas a politizar a justiça e a se deixarem influir pelos fatores reais do poder. Afinal, como afirma Claus Offe, "a tarefa da democracia consiste em buscar a 'democratização' da democracia, apesar de seus perigos reais". ${ }^{44}$ Mais uma vez, a dupla dimensão do direito se erige como base da legitimidade da argumentação em matéria de justiça eleitoral e, também, como base de uma democracia deliberativa.

44 OFFE, 2011, p. 94. 


\section{Referências}

ALEXY, Robert. Theorie der juristischen Argumentation. Die Theorie des rationalen Diskurses als Theorie der juristischen Begründung, Fráncfort del Meno, Suhrkamp, 1978.

, Theorie der Grundrechte, Fráncfort del Meno, Suhrkamp, 1985.

, "Balancing, Constitutional Review and Representation", en, International Journal of Constitutional Law, vol. 3, no. 4, 2005: pp. 572-581.

, Teoria discursiva do direito, Rio de Janeiro, GEN/ Forense Universitaria, 2014.

AARNIO, Aulis, The Rational as Reasonable. A Treatise on Legal Justification, Dordrecht, D. Reidel Publishing Company, 1987.

ATIENZA, Manuel, Curso de Argumentación Jurídica, Madrid, Trotta, 2013.

BERNAL, Carlos, „Die Fundamentalität der Grundrechte“, no, Clérico, Laura y Sieckmann, Jan-Reinard (Eds), Grundrechte, Prinzipien und Argumentation. Studien zur Rechtstheorie Robert Alexys, Baden-Baden, Nomos Verlagsgesellschaft, 2009: pp. 83-97.

BOBBIO, Norberto, "Hegel y el iusnaturalismo", no, Amengual, Gabriel (ed.), Estudios sobre la filosofía del derecho de Hegel, Madrid, Centro de Estudios Constitucionales, 1989: pp. 377-406.

FCE, 2007.

El futuro de la democracia, Cidade do México,

CASTORIADIS, Cornelius, "La polis griega y la creación de la democracia", no, Escritos Políticos, Madrid, Los Libros de la Catarata, 2005: pp. 103-128. 
CELIKATES, Robin, y Gosepath, Stefan, Grundkurs Philosophie, Band 6 Politische Philosophie, Stuttgart, Reclam, 2013.

DE SOUSA, Boaventura, Democracia al borde del caos. Ensayo contra la autoflagelación, Cidade do México, Siglo XXI Editores, 2014.

DICKENS, Charles, Tale of Two Cities, Nueva York, Dover thrift Editions, 1999.

FERRAJOLI, Luigi, Poderes salvajes. La crisis de la democracia constitucional, Madrid, Trotta, 2011.

FUCHS, Dieter, "Demokratie", no, Lexikon Politik. Hundert Grundbegriffe, Reclam, Stuttgart, 2009: pp. 38-43.

GORMAN, Jonathan, "Three Person Justification”, no, Pavlakos, George, Law, Rights and Discourse. The Legal Philosophy of Robert Alexy, Portland, Hart Publishing, 2007: pp. 207-222.

HABERMAS, Jürgen, Faktizität und Geltung. Beiträge zur Diskurstheorie des Rechts und des demokratischen Rechtstaats, Fráncfort del Meno, Suhrkamp, 1992.

Meno, Suhrkamp, 1991.

Erläuterungen zur Diskursethik, Fráncfort del , Conciencia moral y acción comunicativa, Barcelona, Planeta-de Agostini, 1994.

KELSEN, Hans, Verteidigung der Demokratie, edición de Matthias Jestaedt y Oliver Lepsius, Mohr Siebeck, Tubinga, 2006.

KERSTING, Wolfgang, Politik und Recht. Abhandlungen zur Politischen Philosophie der Gegenwart und zur neuzeitlichen Rechtsphilosophie, Velbrück Wissenschaft, Tubinga, 2000.

KUMM, Mattias, “Alexy’s Theory of Constitutional Rights and the Problem of Judicial Review", no, Klatt, Matthias (Ed.), Institutionalized Reason. The Jurisprudence of Robert 
Alexy, Nueva York, Oxford University press, 2012: pp. 201217.

LASSALLE, Ferdinand. Reden und Schriften, Reclam, Leipzig, 1987.

LUHMANN, Niklas, Legitimation durch Verfahren, Fráncfort del Meno, Suhrkamp, 1997.

MAcCORMICK, Neil, Legal Reasoning and Legal Theory, Oxford, Oxford University Press, 1994.

MASTRONARDI, Philippe, Verfassungslehre. Allgemeines Staatsrecht als Lehre vom Guten und gerechten Staat, Berna, Haupt UTB, 2007.

MOUFFE, Chantal e LACLAU, Ernesto, Hegemonía y estrategia socialista: hacia una radicalización de la democracia, Buenos Aires, FCE, 2004.

OFFE, Claus, "Wie der Markt die Politik vergiftet. Die Finanzkrise als Demokratieverlust: Colin Crouchs Lagebericht". Frankfurter Allgemeine Zeitung, 22, 2008: p. 37.

"Demokratie", no, Offe, Claus/Hartmann, Martin, Politische Theorie und Politische Philosophie. Ein Handbuch, Múnich, C. H. Beck Verlag, 2011: pp. 88-94.

PECZENIK, Aleksander, Law and Reason, Dordrecht, Springer, 1989.

RAWLS, John, Teoría de la justicia, Cidade do México, FCE, 2010.

RIEDEL, Manfred, Rehabilitierung der praktischen Philosophie, 2 volúmenes, Rombach, Friburgo, 1972-1974.

ROUSSEAU, Jacques, The Social Contract or Principles of Political Right, Chicago, Enciclopaedia Britannica, 1971. 
SALAZAR, Luis, (Coordenador), ¿Democracia o posdemocracia? Problemas de la representación política en las democracias contemporáneas, Cidade do México, Fontamara, 2014: pp. 7-16.

WEBER, Max, Wirtschaft und Gesellschaft. Grundriß der vertehenden Soziologie, Mohr Siebeck, Tubinga, 1976.

WRÓBLEWSKI, Jerzy, "Legal Decision and its Justification”, no, Hubien, Hubert (ed.), Proceeding of the World Congress for Legal and Social Philosophy, Bruselas, 1971, pp. 409-419.

ZEPEDA, Jesús, “El espacio de los ausentes: discriminación y representación democrática”, no, Salazar, Luis (Coordenador), ¿Democracia o posdemocracia? Problemas de la representación politica en las democracias contemporáneas, Cidade do México, Fontamara, 2014: pp. 221-247.

Recebido em 18/02/2020

Aprovado em 09/02/2020

Alejandro Nava Tovar

E-mail: alextobarkley@gmail.com 